\title{
Allowing for uncertainty in exogenous shocks to CGE models: The case of a new renewable energy sector
}

\author{
Euan Phimister ${ }^{1}$ and Deborah Roberts ${ }^{1,2}$
}

${ }^{1}$ Aberdeen Centre for Research in Energy Economics and Finance, University of Aberdeen Business School, University of Aberdeen AB24 3QY. Email:

e.phimister@abdn.ac.uk; deb.roberts@abdn.ac.uk

${ }^{2}$ Social, Economic and Geographical Sciences group, The James Hutton Institute, Aberdeen AB15 8QH. Email: deb.roberts@ hutton.ac.uk

\begin{abstract}
The paper explores the importance of allowing for uncertainty in the magnitude of exogenous shocks in CGE models. The shock examined is the introduction of a new onshore wind sector in North East Scotland. A simple analytical model is developed to show how, a priori, the size of the new sector (the model shock) is uncertain and asymmetrically distributed as a result of spatial correlation in costs and returns across potential development locations. The importance of allowing for this uncertainty is tested by comparing the results from a CGE model where the sector size is assumed known with certainty to those from a model where the sector size is a random variable with an asymmetric distribution. The results show the extent to which allowing for uncertainty can influence the magnitude of estimated impacts with some variables more sensitive to the uncertainty than others.
\end{abstract}

Keywords: CGE models; uncertain shocks; onshore wind; renewable energy; systematic sensitivity analysis. 


\section{Introduction}

A longstanding criticism of Computable General Equilibrium (CGE) models is that, like input-output models, they are deterministic and provide only point estimates of the impacts of an exogenous shock to an economy. In response to such criticism, Systematic Sensitivity Analysis (SSA) is increasingly being used in CGE model applications as a way of allowing for parameter uncertainty (see, for example, Keeney and Hertel, 2009; Hertel et al., 2010). SSA can also be used to allow for uncertainty in the size of the shock in CGE model applications (see, for example Valenzuela et al., 2007; Horridge and Pearson, 2011; Beckman et al, 2011;Verma et al., 2011). However, it remains standard CGE modelling practice to either a) treat both the shock and model parameters as certain with ad hoc sensitivity analysis carried out on one or more model parameters (see for example, Allan et al., 2007), b) use SSA as a means of recognising uncertainty in model parameters but treat the magnitude of the exogenous shock to the model as certain (see for example, Hertel et al., 2007) or c) explore shock uncertainty through scenario analysis but not using SSA (see for example, Mardones, 2015).

The extent to which this is a problem depends on the nature of the shock being analysed. In some applications, for example a study of the impact of government investment in public sector infrastructure, or a study of the impact of a plant closure in a regional economy, the size of the shock may be relatively certain. In other cases the magnitude of the exogenous shock may be difficult to predict due to its nature (e.g. the impact of climate change) or because it is determined by behavioural forces outwith the direct control of the State (e.g. the impact of in-migration).

This paper explores the importance of allowing for uncertainty in the magnitude of one particular type of exogenous shock to a CGE model: the introduction of a new sector to a regional economy. At a general level, the aims of the paper are similar to 
Rey et al. (2004) in their analysis of the importance of uncertainty in integrated econometric and I-O models. In this case however the scope of analysis is more restricted in that it focusses on just one source of uncertainty with the underlying research question being "Can allowing for uncertainty in the size of an exogenous shock to the CGE model change the magnitude and qualitative nature of results?"

The new sector considered is the onshore wind energy sector. A number of earlier studies have measured, ex ante, the economy-wide benefits of onshore wind but have assumed that the size of the new sector has been known with certainty. In reality, the eventual size of the new sector is determined by the interplay between uncertain technical and economic considerations as well as, in the UK context, the outcome of a planning process where each individual development is considered on a case by case basis.

To illustrate how this results in uncertainty in terms of the shock, a theoretical model is developed within which the supply of new onshore wind developments is taken as dependant on the distribution of wind resources (and hence revenue) across alternative locations as well as the distribution of actual and opportunity costs of each potential development. The distribution of wind resources in a region can be observed but is uncertain with the potential revenues of alternative sites being spatially correlated. The distribution of actual and opportunity costs are also are argued to be spatially correlated but unobserved. As a result, the equilibrium size of the new sector being not only uncertain but also asymmetrically distributed.

Building on this, a CGE modelling approach is used to assess the impact of a new onshore wind sector in the case study region - North East Scotland. The shock is modelled as a supply-side shock by introducing a new sector to the regional economy, increasing the amount of energy produced in the region. The results from two versions 
of the model are compared. In the first version it is assumed that the size of the sector is known with certainty. This is henceforth referred to as the deterministic version of the model. In the second version, the size of the sector is treated as an unknown random variable distributed according to a left triangular distribution with a given expected value and variance. This is henceforth referred to as the uncertain version of the model.

The findings confirm that the magnitude of impacts is sensitive to assumptions on the underlying distribution of the shock. In particular, the deterministic version of the model appears to underestimate the impacts of the new sector relative to the uncertain case with some variables, including sector GDP and those relating to welfare effects, more sensitive to uncertainty than others.

The structure of the paper is as follows. The following section provides the context for the empirical analysis, and presents a simple model highlighting the factors that will influence the equilibrium level of installed onshore wind capacity (and thus sector size) at a regional level. Section 3 presents an alternative, computationally efficient, method of conducting SSA when dealing with asymmetrically distributed random variables to that suggested by DeVuyst and Preckel (2007). Section 4 describes the underlying CGE model, SAM and simulation methods. Section 5 presents the results while section 6 concludes and suggests further research on allowing for uncertainty in CGE models.

\section{Factors influencing the growth and size of the onshore wind sector}

In response to increasing concern surrounding the security of energy supplies and the impacts of climate change, several new renewable energy sectors have developed over the last decade. These include onshore and offshore wind, solar energy, hydropower, and a variety of different sectors focussed on exploiting the energy potential of biomass. In most cases, growth has been encouraged and supported by 
government policies. Many of the new sectors are based in remote rural areas and policy documents often make reference to the economic benefits that renewable energy generation brings to the regions in which they are located. In particular, in addition to their contribution to energy security and environmental goals, the growth in renewable energy is argued to bring new sources of income and employment to regions which tend to have limited alternative opportunities and an overdependence on primary sectors (agriculture, forestry and mining).

Growth in renewable energy generation in Scotland, as elsewhere in the UK, has been strong over the last decade. The current Scottish Government has ambitious renewable energy targets, aiming to produce the equivalent of $100 \%$ of its domestic electricity demand through renewables by 2020. Growth in onshore wind has, to date, contributed most towards achieving this target with capacity growing from around 300MW to over 4300MW between 2003 and 2013 (DECC, 2014).

Within the case study region for this analysis, North East Scotland, the capacity of the onshore wind sector has developed from a starting point of zero in 2005 , to a situation where, at time of writing, over 400MW of onshore wind power is either operational or has planning consent (Aberdeenshire Council, 2016). This rapid increase has been attributed to the suitability of region for wind energy production, the relatively positive approach of the local council to such developments and the progressive and innovative nature of local businesses. In particular, farm business involvement in the wind energy sector has increased rapidly due to the switch in government support from a Renewables Obligations Certificate scheme (which favoured larger externally-owned developments) to a Feed-in-Tariff scheme which favours smaller developments. As a consequence, while initially developments were led by commercial companies, farmer- 
owned schemes now account for an estimated $70 \%$ of developments in the region (Bell and Booth, 2010; North East Scotland Agricultural Advisory Group, 2016).

Although operating within higher-level national and regional frameworks, the nature of the planning process in the region (as elsewhere in the UK) is such that each proposed wind development is considered on an individual basis. The process is costly, often takes considerable time and the risk of not getting approval is high and increasing, (Haggett et al., 2013) as a result of, for example, technical constraints including access to grid connections and cumulative visual effects (Sutherland et al, 2014).

A number of previous studies have measured the economy-wide benefits of onshore wind using either input-output or CGE modelling frameworks (Trink et al.2012; Caldés et al., 2009; Simola, 2010; Phimister and Roberts, 2012; Allan et al., 2011). In order to model ex-ante the impact of a new onshore wind sector, an estimate of the size of the new sector is required. To date, to the authors' knowledge, all studies have assumed that the size of the new sector has been known with certainty. However, from a theoretical perspective, the ultimate size of the onshore wind sector will be determined by the interplay between technical and economic factors, which constrain the opportunities for developments and thus the supply of planning applications from developers, with the factors influencing the the planning process and, in particular, whether or not applications are approved (which could be viewed as a proxy of the demand for developments). Together these will determine an equilibrium level of installed wind capacity which can then be translated into a supply-side economic shock to an economy. However, differences in the opportunities, costs, and expectations of future returns for individual developments across locations, along with differences in the way in which the planning process reflects local preferences for wind, mean that the ultimate level of installed capacity is highly uncertain. 
The following simple model illustrates the interaction between developer decisions and the planning process, thus highlighting the resulting sources of uncertainty in the equilibrium size of the sector. For ease of exposition, it is assumed that the landowner is also the potential developer (as is the case for farmer-owned wind installations). ${ }^{\mathrm{i}}$

Assume there are $\mathrm{N}$ possible locations (indexed by $i$ ) in the region where wind turbines could be installed. At each location, the landowner can decide whether to make an application for a level of installed capacity $y$. For simplicity, assume that each location faces a potential instantaneous wind production $y^{p}$ drawn from known distribution $f\left(y^{p}\right)$. When wind production, $y^{p}$, is below installed capacity, output at that instant will equal potential wind output. When $y^{p}$ is higher than capacity, output at that instant will equal capacity. If the production phase of the project is assumed to be total length $T$, expected output over the project will be $\left(\int_{0}^{y} y^{p} f\left(y^{p}\right) d y^{p}+\int_{y}^{\infty} y f\left(y^{p}\right) d y^{p}\right) T$.

Any planning application faces a given probability of approval $q$, known net revenue per unit of electricity output $p,{ }^{\mathrm{ii}}$ location specific project $\operatorname{costs} c\left(y, \varepsilon_{i}\right)^{\mathrm{iii}}$, and cost of capital $r\left(\varepsilon_{i}\right)$. The differences in costs are assumed to arise from differences in the distance to the grid and topography across locations which affect development and grid access costs. Differences in opportunity cost of capital may arise due to credit constraints and attitudes to risk which can be important in agriculture (e.g. see Benjamin and Phimister, 2002; Sckokai and Moro, 2006). It is assumed that the distribution of the possible costs $\varepsilon$ are known and spatially correlated but not observed. 
For simplicity we consider a two period model with the first capturing the application phase and the second, the development and production phase (if the application is approved). ${ }^{\text {iv }}$

At each location, the landowner will choose to maximize the expected net present value.

$$
\operatorname{Max}_{y} E[N P V]=\frac{q p T}{1+r\left(\varepsilon_{i}\right)}\left(\int_{0}^{y} y^{p} f\left(y^{p}\right) d y^{p}+\int_{y}^{\infty} y f\left(y^{p}\right) d y^{p}\right)-c\left(y, \varepsilon_{i}\right)
$$

This problem is analogous to simple inventory models under demand uncertainty. From the first order condition to (1), the following marginal condition can be obtained which defines the optimal level of capacity to apply for at a specific location $i$ given $\varepsilon_{i}$

$$
q p T\left(1-\operatorname{Pr}\left[y^{p} \leq y^{*} \mid\right]\right)=\left(1+r\left(\varepsilon_{i}\right)\right) c^{\prime}\left(y, \varepsilon_{i}\right)
$$

The right hand side of equation (2) is the marginal investment cost which is set equal to the expected marginal return allowing for both the probability of planning permission and the probability that potential wind output at any instant is below installed capacity. Equation (2) can be used to define a supply function for a specific location $y\left(q, p, \varepsilon_{i}\right)$ so that, at any particular location, the actual level of application for wind capacity will be defined by

$$
y_{i}=\max \left[y\left(q, p, \varepsilon_{i}\right), 0\right]
$$

Summing over all locations implies the existence of an overall supply function for applications for the region which is a function of distribution of wind energy 
production, other technical resource constraints such as grid connection opportunities and available farmland, location-specific cost of capital, other general costs.

$$
Y(q, p, \varepsilon)=\sum_{i=1}^{N} \max \left[y\left(q, p, \varepsilon_{i}\right), 0\right]
$$

We do not model the planning system explicitly but recognise that it determines the probability that an application is accepted. As part of this we assume that the overall probability of a planning application succeeding will decline with the level of total applications.

$$
q=q(Y)
$$

This may be thought to reflect the preferences of local voters and the politicians or simply that planning rules are such that planning officers recommendations to accept or reject a proposal take existing capacity into account.

Equations (4) and (5) define an equilibrium level of total planning applications $\left(Y^{*}\right)$ and probability of acceptance $\left(q^{*}\right)$ with the ultimate (saturation) level of installed capacity $q^{*} Y^{*}$

In this simple setting, the uncertainty in the size of the sector (the shock to the model) arises from uncertainty in potential wind production and the lack of knowledge of the actual values of $\varepsilon_{i}$. The size of the wind sector ex ante should thus be considered as uncertain with a distribution reflecting the nature of the joint distribution of $\varepsilon_{i}$ across locations.

At any location $i$ (conditioning on the outcomes at other locations), it follows from (3) that the supply of applications will be truncated at zero. This in turn implies that $y_{i}$ 
will have an asymmetric and positively skewed marginal distribution. If the cost shocks are independently distributed, it follows from equation (4) and the central limit theorem that modelling the aggregate level of $\mathrm{Y}$ as approximately normally distributed is likely to be adequate most situations. However, in this case the joint distribution of the $\varepsilon_{i}$ across locations is expected to be spatially dependent, with outcomes in adjacent locations positively correlated. For example, both development costs and landowner attitudes are likely to be positively correlated across neighbouring locations. As a result, the asymmetric properties of the underlying $y_{i}$ are likely to be inherited by the distribution of overall applications $Y$.

To test this, a Monte Carlo simulation model was constructed, assuming $f\left(y^{p}\right)$ as a Weibull distribution and the conditional marginal distribution of $\varepsilon_{i}$ as symmetric triangular, while spatial dependence across simulated locations was captured using a symmetric Delaunay spatial weight matrix (Kelley Pace, 2003). This showed that, for the specific parameter values chosen, positive skewness in the overall distribution of $Y$ increases with the correlation in potential revenues and costs between nearest

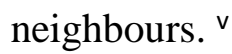

In summary the theoretical model shows that while we lack information on the exact nature of the probability distribution which should be used to evaluate the impact of a new onshore wind sector, we should consider in the analysis a shock which is both random (uncertain) and asymmetrically distributed. 


\section{Using Systematic Sensitivity Analysis (SSA) to account for uncertainty in model shocks}

Monte Carlo simulation provides the usual starting point for a SSA (Abler et al., 1999), however the utility of this approach is constrained by the number of parameters typically treated as jointly uncertain in CGE models. Gaussian Quadrature has provided a range of results and methods for reducing the dimensionality of the problem (DeVuyust and Preckel, 1997, 2007; Domingues and Haddad, 2005). This involves the moments of the joint distribution of the parameters being approximated using a discrete joint probability distribution evaluated over a finite number of points. The simulation values of interest (for example, regional GDP) can then be found by evaluating the model at these points and constructing a weighted average.

If the uncertain parameters are assumed jointly independently and symmetrically distributed, then it is possible to apply the Stroud points and approximate the first and second moments of the joint distribution of the parameters. For such special cases, the dimensionality of the problem can be significantly reduced. In particular, with $n$ parameters modelled as random variables, the expected values and variances for model outcomes of interest can be obtained using the Stroud formula from only $2 *$ n separate evaluations of the model (Stroud, 1957). However a potentially significant limitation in Stroud implementation of SSA is the assumption of symmetry of the underlying distributions. Based on the discussion in section 2, there is no a priori reason for assuming a symmetric distribution in the case of the onshore wind sector, indeed the theoretical model suggests the underlying distribution of the size of the sector will be positively skewed.

In the case of non-symmetric distributions, Gaussian Quadrature weights and evaluation points for any general distribution can be derived from a suitably defined 
Linear Programme (LP) (DeVuyst and Preckel, 2007). DeVuyst and Preckel's (2007) general approach to finding a solution to the associated LP problem is first to define the underlying distribution, $f(X)$, and obtain the associated known moments which define the right hand side of the LP constraints. Following this, the approach involves finding a large number of points $x_{i k}$ within the domain of the integration and then solving the LP problem. While such an linear programme is straightforward to define, its size expands rapidly as the number of parameters involved increases (Arndt et al, 2006). This limits its potential usefulness for general SSA involving a large number of parameters although linear dependencies between the constraints mean that quadratures can be found with many fewer points than the number of LP constraints. ${ }^{v}$

Even for problems where a limited variables are to be considered random and where it is feasible to use Monte Carlo, the reduction in dimensionality provided by the quadrature is computationally attractive. However, a potential issue - at least in the general case where the distributions of the random variables in $X$ are not independent is that finding the initial values which define a quadrature (for use as the basis for the LP) can be difficult.

This potential difficulty is avoided in this analysis by a simple adaption of the DeVuyst and Preckel procedure. The first step proceeds as before, i.e. the distribution is defined and appropriate population moments constructed. Following this, a number of random samples from this distribution are drawn and used to calculate the associated sample moments for this data. Then, rather than the actual population moments, we use the sample moments to define the right hand side constraints of the LP system while the drawn random samples define the left hand side values of the constraints. By definition, the solution including all points with equal weights is guaranteed to be feasible in this problem. One obvious limitation of this approach is that the quadrature 
obtained is now not defined for the population moments but rather is an approximation to them. However, the extent of the errors induced is likely to be small and can be tested. ${ }^{\text {vii }}$ We use this amended quadrature approach in this analysis, with degree $3 \mathrm{GQ}$ weights and points constructed for an SSA for the size of the new wind sector. To the authors' knowledge this approach to allowing for non-symmetric distributions has not previously been implemented in a CGE model.

\section{The model and simulation approach}

\section{The regional CGE model}

The model used in this analysis is a bi-regional comparative static CGE model adapted to make it appropriate for analysis of the impacts from a new onshore wind sector in a small and geographically isolated regional economy, North East Scotland. The region is defined by two Local Authority areas, Aberdeen City and Aberdeenshire (Scottish Government, 2016a). The production sectors in the model have been disaggregated to differentiate between sectors based in the rural (Aberdeenshire) and urban (Aberdeen city) parts of the region. This provides a means of exploring the extent to which the benefits of onshore wind (located in the rural part of the region) are retained by other local businesses and residents or are leaked to urban parts of the region. Three categories of households are recognised: rural, urban and farm households, the latter split by size of farm. The model recognises the significant levels of commuting in the region, from rural Aberdeenshire to urban Aberdeen City (NOMIS, 2016), with factor incomes flowing to households depending on their place of residence. In contrast, commodity markets are treated as unified with a single set of commodity accounts for both the rural and urban parts of the region. The structure of the SAM is shown in Figure 1. 
As is standard in CGE models, production is based on the assumption of cost minimising behaviour of producers. A two layered production function is specified where, at the top level, technology is modelled as a CES function combining quantities of value added and aggregate intermediate input and, at the bottom level, intermediate demand is determined assuming fixed input-output coefficients.

Factor earnings from each production activity (including, in the model simulations, earnings from the new onshore wind sector) are distributed to households depending on ownership structure and/or the provision of factor services. Reflecting the dominance of owner-occupation in the Scottish agricultural sector $(77 \%$ of farmers are owner occupiers, Scottish Government, 2015) and the importance of farmer-owned renewable developments in the region, the new sector is treated as owned and operated by farm households, mapping income from onshore wind energy generation into the farm household accounts. The labour market is segmented to distinguish between skilled and unskilled workers with wages and employment levels solved endogenously within the model (Thurlow, 2008). In contrast, capital and land factors are treated as fixed and immobile between sectors. viii

There are four components of final demand: consumption, investment, government expenditure and exports. Household consumption is modelled as LES demand function of real disposable income. The Government account collects taxes and transfer payments and then uses this income to purchase commodities, provide transfers to other institutions (e.g. households). The subsidy for renewable investment is treated as being exogenous, given from the UK government with the required government balance ensured by allowing government savings to adjust endogenously. The external balance is achieved assuming fixed levels of investment but allowing for flexible out-of region 
savings. This choice of closure is the same as that used by Julia-Wise et al., (2002) and Waters et al., (1997) in their CGE model analyses of small regions.

Exports (and imports) are determined using the Armington approach. In other words, regional market demands are assumed to be for a composite good made up of a CES-determined combination of regional output and imports where the two are imperfect substitutes. Similarly, regional output is derived by aggregating across all potential regional sources of supply and then split into that consumed within the region and exported using a CET function. ${ }^{\text {ix }}$

The model is restrictive in terms of its ability to model potential feedback effects between the region and the wider UK and international economy In particular, the subsidies given to support the new renewable sector are treated as exogenous (from the UK government) and there is no account taken of possible feedback effects from this in terms of increased local domestic electricity prices. Although within region labour mobility is accommodated in the model, overall population levels are assumed fixed so no inter-regional migration can occur in response to the shock. The model also ignores the impact of the increased electricity generation on the wholesale UK electricity market and on fossil fuel generation. The increase in generation may give rise to negative displacement and price effects at UK level which would feedback into the region. However, given the small size of the region $(9.4 \%$ of the Scottish population are resident in North East Scotland (Scottish Neighbourhood Statistics, 2016), its relative geographical remoteness (reducing the likelihood of inter-regional migration), and the limited size of shock being analysed, the magnitude of any feedback effects on the estimated impacts are likely to be very small. The restrictions thus do not detract from the underlying (methodological) aim of the paper to show the importance of allowing for uncertainty in CGE model shocks. 
A SAM consistent with the model structure was constructed with a base year of 2005. This provided a numerical account of the flow of income in and around the region immediately prior to the development of the onshore wind sector. As noted above the SAM was bi-regional, in that production and household accounts were split to distinguish between businesses and households resident in rural Aberdeenshire Local Authority area from those located in urban Aberdeen City Local Authority area. This definition of rural and urban is cruder than the two-fold definition adopted by the Scottish Government (Scottish Government, 2016b) with the rural area including several towns which have a population of more than 3000 residents. However adopting administrative boundaries made the SAM construction process far easier than would otherwise be the case as the required secondary data from official sources was available at Local Authority level.

The construction process involved an initial mechanical regionalisation of Scottish input output tables, based on employment quotients, and the subsequent improvement and/or further disaggregation of initial estimates using detailed statistics on the agriculture and energy sectors. The final balanced SAM was generated using cross entropy methods (Robinson et al., 2001).

The base year SAM distinguishes 48 production sectors, distinguishing farms by size (those 40 ESUs or over classified as large, the remainder small) and farm type (crop, livestock and "other"). Households resident in Aberdeen City local authority area are classified as urban, the remainder (excluding farm households) as rural, and farm households split according to the size of the farm. Table 1 provides summary information on the case study region as derived from the SAM. 


\section{INSERT TABLE 1}

\section{Model simulations}

The model simulations involve a new onshore wind sector plus a wind specific capital factor being introduced into the model. In other words, a supply side shock to the economy is modelled with the costs and revenues of the new sector and factor account based on the values given in Table 2 . The analysis focuses on the medium run impact of the new sector (the construction phase is not modelled).

\section{INSERT TABLE 2}

Operating and maintenance costs of the new sector are allocated over skilled and unskilled labour categories, with small proportions of these costs allocated to commodities demanded (insurance, construction, transport, other services and other manufacturing). These values are then used to derive input-output coefficients for the intermediate demand for the new sector. The CES elasticity of substitution is set equal to the value used for the other production sectors and a value added function parameter was obtained, consistent with the calibration process for the other sectors.

The annual gross revenue of the new wind sector is taken as $£ 260 \mathrm{~K}$ per MW installed in 2005 prices. Broadly consistent with the typical Renewable Obligations Certificates $\left(\right.$ ROC) ${ }^{x}$ values between 2005-2010, half the revenue is assumed to be derived from subsidy payments, with the remainder arising from electricity sales. Annual financing costs and income are treated as the factor payments to capital specific to the onshore wind sector. As noted above, the new sector is assumed owned by 
farmers and farm households are assumed to be the sole residual claimants on factor income after capital costs have been paid.

The model is first calibrated to the 2005 base case, and then the new onshore wind sector is added to the model as a supply shock using the input-output and elasticity assumptions described above. The size of the sector is captured by introducing a specific factor of production for this sector only, and the model calibrated to reflect the capacity utilisation (load factor) for onshore wind.

In order to assess the importance of allowing for uncertainty, the model is run twice. In the first it is assumed the size of the sector is known with certainty. Based on growth in installed wind energy capacity in the region to date, the size of the sector in the deterministic version (where the size of the new sector is taken as known with certainty) is taken as 500MW. In the second version of the model, which allows for uncertainty, the size of the sector is treated as a random variable asymmetrically distributed above and below the expected value of 500MW with a minimum value of 300MW a maximum value of $900 \mathrm{MW} .^{\mathrm{xi}}$

In the absence of information on how farm households use revenue from renewable energy developments, two alternative scenarios are explored. In the first, it is assumed that the extra income associated with the new renewable sectors is received by farm households and then allocated primarily to consumption. This is, henceforth, labelled the "Consumption" scenario.

Research suggests that the EU's Common Agricultural Policy (CAP) direct payments (which are payments to farmers regardless of their level of production) have impacts on farm investment decisions due to farmer risk preferences (Sckokai and Moro, 2006). There is also evidence of binding credit constraints in UK agriculture (Benjamin and Phimister, 2002). Both of these factors, together with the argument that 
farmers see farming as a "way of life", could lead to farm households using the factor income from the new renewable sector to increase capital stock in agricultural activities. The second scenario is, henceforth, labelled the "Investment" scenario and reflects this situation, assuming that the extra income associated with the new sector is re-invested in agricultural capital.

To implement the investment scenario, we take the capital factor payments of the onshore wind sector from the first set of simulations as the value of additional investment in the economy (i.e. after allowing for interest capital repayments). The resulting increase in capital stock is estimated by assuming that the published values for gross fixed capital formation in agriculture are steady state values (that is they maintain capital stock at 2005 values). The factor income allocated to extra investment in each scenario is then assumed to increase the steady state capital stock in the agriculture sectors relative to their base Gross Fixed Capital Formation (GFCF) values with new capital stock allocated across the agricultural sectors in proportion to base year capital factor payment levels.

In summary the new sector is modelled as a supply-side shock to the regional economy with all factor income from the new sector flowing to farm households. Two versions of the model are run, one where the size of the sector is known with certainty, and the other where it is treated as a random variable with known distribution. The sensitivity of the results to the way in which the new factor income is spent is explored by comparing two scenarios: one where it is assumed the additional income is spent by farm households in the same pattern as observed in the base year; the other where it is assumed the additional income is invested in the agricultural capital. 


\section{Results}

Table 3 reports the overall impact on GDP of the new onshore wind sector as estimated under each alternative version of the model. The table reports both the absolute change and percentage change in GDP from base year levels. For the random shock, the results come in the form of point estimates with their associated coefficients of variation $(\mathrm{CV})$ shown in brackets. Lower $\mathrm{CV}$ s indicate results in which we can have confidence and vice versa. Because the model is not an explicitly dynamic, it is difficult to state the time it takes for the model to reach its new equilibrium state but typically CGE model results are interpreted as medium run effects. This is broadly consistent with the time it has taken for the sector to become established in the case study area (around 10 years).

\section{INSERT TABLE 3}

Overall, the distribution of GDP effects across rural-urban space follows the same pattern across both scenarios with rural GDP rising (most notably under the investment scenario), urban GDP falling slightly. The impacts on GDP are explored further in Table 4 which splits the total GDP impacts into impacts on the different types of sectors - agriculture, manufacturing and services - in each part of the region. Here the differences in the consumption and investment scenarios is more obvious with agricultural GDP increasing more than $20 \%$ in the investment scenarios, but falling slightly in the consumption scenario once price, factor and other adjustments in the system take place.

\section{INSERT TABLE 4}


To explain how the effects of the the new sector come about, we focus on the the consumption scenario in the deterministic version of the model. ${ }^{\text {xii }}$ Here the overall GDP impact is positive but small with total GDP estimated to increase by $£ 100.21 \mathrm{~m}$ $(1.13 \%)$. Closer analysis of the results shows that this arises primarily from the direct effect of the new onshore wind sector on rural GDP. There is a very slight negative impact on other sectors (in both rural and urban parts of the region) as the new sector increases overall demand for skilled and unskilled labour. This causes wages to rise rise slightly $(+0.1 \%$ for unskilled and $+0.5 \%$ for skilled labour) which negatively impacts on other sectors, particularly the service sectors.

In the investment scenario, focussing again focussing on the deterministic version of the model, as anticipated, total GDP benefits are higher rising by $£ 116.69 \mathrm{~m}(1.31 \%)$. Here the primary effect of the new sector is similar to the consumption scenario. However, in addition, the re-investment in agricultural capital boosts agricultural output which leads to a fall in aggregate prices of domestically produced crop and livestock aggregate output (by $-2 \%$ and $-4 \%$ respectively). This, in turn, benefits the regional food processing sectors in the model, with the Fruit, Vegetables and fish products sector increasing regional exports by $0.6 \%$, the "Other food" sector (including meat and meat products) by $2.9 \%$ and regional consumption of the commodities from these sectors increasing by $0.5 \%$ and $1.5 \%$ respectively. As a result the demand for labour in the agricultural and food processing sectors rise and regional wages rise slightly more than in the consumption scenario $(+0.2 \%$ for unskilled and $+0.7 \%$ for skilled labour), which has further small negative impacts on other sectors.

Looking specifically at the energy sector, the introduction of the new onshore wind sector significantly increases the regionally produced energy aggregate $(+30 \%)$ and this 
is associated with a small fall in its price $(-0.6 \%)$, a large increase in exports of the energy commodity $(+33 \%)$, a fall in imports $(-42 \%)$, and a very small increase in energy consumption within the region $(+0.2 \%)$.

While the differences across the two alternative model versions is not large, the results suggest that the underlying distribution of the shock does matter. In particular, in this particular case the deterministic model underestimates the aggregate level GDP impacts relative to the model which allows for uncertainty. For example, in the case of the investment scenario, the introduction of a new onshore wind sector to the North East Scotland economy is estimated to increase total GDP by $£ 122.8 \mathrm{~m}$ when the size of the sector is treated as uncertain around an expected capacity of 500MW as compared to an increase of $£ 116.69 \mathrm{~m}$ when the size of the new sector is assumed to be exactly 500MW.

The results Table 4 show that allowing for uncertainty can have differentiated impact on results with agricultural GDP (investment scenario) and urban manufacturing GDP (consumption scenario) having lower expected values in the uncertain run of the model than in the deterministic run of the model. More generally, some of the sector GDP values in the final two columns of Table 4 have high coefficients of variation, particularly the rural manufacturing, urban services and (in the investment scenario) the agriculture sector results. By providing such information on the robustness of model results, SSA has a clear advantage over more standard deterministic approaches to CGE analysis.

Table 5 reports the welfare effects associated with each of the simulations where welfare is measured in terms of the equivalent variation (EV), the monetary equivalent of how much better off (or worse off) households are in consumption terms after the 
introduction of the new sector compared to their unobserved base year welfare level (Blonigen et al., 1997).

\section{INSERT TABLE 5}

The development of the new wind sector is shown to give rise to negative welfare effects for all but farm households (the owners of the new sector). Farm households, particularly those with large farms, benefit significantly from the development of the new sectors. Similar to the GDP results, the results in Table 5 suggest that the underlying distribution of the shock matters with the (absolute) impact the shock in some cases larger, in some cases smaller in the uncertain version of the model compared to the deterministic case. As in Table 4, some of the EV values in the final two columns of Table 5 have high coefficients of variation, particularly the EV for (non farming) rural households which feeds through into the total EV result.

\section{Discussion}

CGE models are often used to estimate, ex ante, the impact of exogenous shock to an economy assuming that the precise magnitude of the shock is certain. This paper has explored the importance of allowing for uncertainty in the magnitude of a shock using, as a case study, an analysis of the impact of a new onshore wind sector in a regional economy. SSA is used as the means of reflecting uncertainty in the shock. While there are previous studies which have explored uncertainty in CGE model shocks, these are relatively rare and instead the standard practice is to use SSA to allow for uncertainty in model parameters only, or to treat both the shock and parameters are 
certain and use more restrictive ad hoc approaches to test for the sensitivity of the results.

A simple theoretical model was developed showing the factors influencing both the supply of and demand for wind farm developments in the region. The model highlights the importance of the (known) distribution of wind potential and (unknown) distribution of costs across potential wind farm locations, and also the spatial dependence of these variables. It suggests that the equilibrium size of the onshore wind energy sector in the region (the shock to the model) is not only uncertain but its underlying probability distribution is asymmetric. The latter creates some difficulties in implementing SSA and a new adaptation to DeVuyst and Preckel's (2007) GQ approach (using sample moments to initiate the linear programming) is suggested to facilitate the use of SSA in CGE models with non-symmetrically distributed variables.

Growth in renewable energy generation is often argued to bring economic benefits to the regions within which the developments are located. The findings suggest that the regional economic impacts from the introduction of a new onshore wind energy sector are limited in magnitude and restricted to the rural part of the region. Even in the scenario where income from the sector is assumed re-invested, the benefits are largely restricted to the owners of the wind farms, in this case farm households. This reflects the nature of wind energy generation and the fact that there are limited technological linkages to other sectors in the economy and low labour requirements once the developments are operational. The approach adopted in the study can easily be applied to analyse the impact of other new renewable energy sectors including, for example, energy from biomass where, due to higher direct labour requirements and substitution effects in production, the economy-wide effects are likely to be more significant. It could also be extended to explore the sensitivity of the findings to ownership 
assumptions contrasting, for example, the case where the developers are local businesses as in this analysis to that where developments are owned by commercial companies with different technical and economic constraints, and benefit from both economies of scale and scope (Harnmeijer et al., 2016).

In relation to analysis of the onshore wind sector, there is potential to extend the underlying model so as to allow for potential time-dependant effects in the planning process. In particular, due to the negative landscape impacts of onshore wind developments and planning regulations which restrict developments in certain areas, the likelihood of any particular development being approved by planning may be conditional on the size of the sector when the particular application is made. It would therefore be useful to model more comprehensively the planning process so as to better understand the dynamics of interactions between the demand and supply of planning applications which will ultimately determine the size of the sector. Related to this, the current model does not consider the issue of the time taken for the new sector to develop but focusses instead only on the equilibrium size of the shock. To allow for both the size and the timing of the shock would require an explicitly dynamic CGE model.

From a more general methodological perspective, the results show that CGE model results are sensitive to assumptions regarding the nature of the shock. In this case study, ignoring the uncertainty seems to bias the results, particularly those relating to welfare. Treating the shock as deterministic appears to underestimate aggregate-level GDP impacts relative to the asymmetric case. However, when looking at more disaggregated variables such as sector GDP, the direction and magnitude of differences in estimated impacts varies across the alternative versions of the model. The supply and demand for other types of renewable energy developments are also likely to be influenced by spatial affects and thus uncertain and asymmetrically distributed. It follows that CGE models 
which set out to predict the economy-wide impact of such sectors should allow for both uncertainty and asymmetry in their analyses.

An obvious useful extension of the current paper would be to extend the scope of the SSA to explore the relative importance of allowing for both uncertainty in the shock to the CGE model and uncertainty in model parameters. Rey et al. (2004) found no clear answer to the most important source of uncertainty for integrated econometric I-O models. Instead they found that this depended on the focus of the analysis and the variables that were of central concern. While it is tempting to hypothesise that the same would be the case for CGE models, more rigorous empirical testing of uncertainty across the various dimensions of CGE models and in relation to different types of CGE models (national versus regional; comparative static versus dynamic) would be useful. The adaptation to DeVuyst and Preckel's (2007) GQ approach used in this paper could, if further developed also provide a useful basis for such an extended SSA by providing a means of allowing for correlated random variables.

Although just an initial step, the current paper highlights an issue which has received relatively little attention to date - the importance of allowing for uncertainty in shocks to CGE models - and proposes a means of addressing the issue. In doing so, it will hopefully improve the usefulness of CGE modelling for those trying to better understand the impact of new sectors or, more generally, economic development trajectories. 


\section{References}

Aberdeenshire Council (2016) Energy.

https://www.aberdeenshire.gov.uk/business/support-and-advice/industry-

sectors/energy/energy/ (Accessed January 2016)

Abler, D.G., Rodreiguez, A.G. and Shortle, J.S. (1999) Parameter uncertainty in CGE modelling of the environmental impacts of economic policies. Environmental and Resource Economics 14: 75-94.

Allan, G., McGregor, P. and Swales, K. (2011) The Importance of Revenue Sharing for the Local Economic Impacts of a Renewable Energy Project: A Social Accounting Matrix Approach. Regional Studies, 45 (9): 1171-1186

Allan, G., Hanley, N., McGregor, P., Swales, K. and Turner, K., (2007). The impact of increased efficiency in the industrial use of energy: a computable general equilibrium analysis for the United Kingdom. Energy Economics, 29(4): 779-798.

Arndt C., Kozlitina, J., and Preckel, P. (2006) Efficient Survey Sampling of Households via Gaussian Quadrature. Journal of the Royal Statistical Society. Series C (Applied Statistics), 55 (3): 355-364.

Beckman, J., T Hertel and W Tyner Validating energy-oriented CGE models, (2011) Energy Economics 33:799-806.

Bell J and Booth, E (2010) The economic benefits of on-farm wind energy clusters in Aberdeenshire. SAC Consulting

Benjamin, C. and E. Phimister. (2002) 'Does capital market structure affect farm investment? A comparison using French and British farm level panel data' (2002) American Journal of Agricultural Economics. 84(4): 1115-1129.

Caldés, N., Varela, M., Santamaría, M. and Sáez, R. (2009) Economic impact of solar thermal electricity deployment in Spain. Energy Policy 37: 1628 - 1636.

DECC, (2014) Regional Renewable Statistics, Department of Energy and Climate Change https://restats.decc.gov.uk/cms/historic-regional-statistics/ Cited 10 January 2014

DeVuyst EA and Preckel PV (1997) Sensitivity analysis revisited: A quadrature-based approach Journal of Policy Modeling 19(2): 175-185

DeVuyst EA and Preckel PV (2007) Gaussian cubature: A practitioner's guide. Mathematical And Computer Modelling 45(7-8): 787-794

Domingues, E.P. and E.A. Haddad (2005) Sensitivity Analysis in Computable General Equilibrium Models: An Application for the Regional Effects of the Free Trade Area of the Americas (FTAA) Brazilian Review of Econometrics 25(1): 115137.

Donald, S.G., Green D.A. and Paarch H.J (2001) "Differences in Wage Distributions between Canada and the United States: An Application of a flexible estimator of 
distribution functions in the presence of covariates", Review of Economic Studies, 67: 609-633.

Haggett, C., Creamer, E., Harnmeijer, J., Parsons, M., Bomberg, E. (2013). Community Energy in Scotland: the Social Factors for Success, ClimateXChange / Scottish Government.

Harnmeijer,J., Harnmeijer,A., Bhopal, V., Robinson,S., Phimister, E., Roberts,D. and Msika, J. (2015) The comparative costs of community and commercial renewable energy projects in Scotland. Climate Exchange, Edinburgh. http://www.climatexchange.org.uk/reducing-emissions/comparative-costs-communityand-commercial-renewable-energy-projects-scotland/

Hertel, T. , Golub, A., Jones, A., O’Hare, M., Plevin, R. and Kammen, D. (2010) Effects of US maize ethanol on global land use and greenhouse gas emissions: Estimating market mediated responses. BioScience, 60 (3): 223-231.

Hertel, T., Hummels, D., Ivanic, M., and Keeney, R. (2007) How confident can we be of CGE-based assessments of Free Trade Agreements? Economic Modelling 24 (4): 611-635

Horridge, M and K Pearson, 2011. "Systematic Sensitivity Analysis with Respect to Correlated Variations in Parameters and Shocks," GTAP Technical Papers 3496, Center for Global Trade Analysis, Department of Agricultural Economics, Purdue University.

Julia-Wise, R., Cooke, S.C, and Holland, D. (2002) A computable general equilibrium analysis of a property tax limitation initiative in Idaho, Land Economics, 78 (2), 207-227.

Keeney, R. and Hertel T. (2009) The indirect land use impacts of United States biofuel policies: The importance of acreage, yield and bilateral trade responses. American Journal of Agricultural Economics, 91(4): 895-909.

Lofgren, H, Harris, R.L., Robinson, S. (2002) A Standard Computable General Equilibrium Model (CGE) in GAMS, Microcomputers in Policy Research 5, IFPRI, Washington. www.ifpri.org/pubs/micocom/mico5.htm.

Mardones, C. (2015) An Income Tax Increase to Fund Higher Education: A CGE Analysis for Chile, Economic Systems Research, 27:3, 324-344,

NOMIS (2016) Location of usual residence and place of work by sex http://www.nomisweb.co.uk/census/2011/WU01UK/chart/1132462448 (Accessed January, 2017)

North East Scotland Agricultural Advisory Group (2016) The Land Based Sector in North East Scotland: Facing the Future . http://www.aberdeenshire.gov.uk/business/support-and-advice/industrysectors/agriculture-and-rural-development/facing-the-future/ (Accessed January 2017). 
Phimister, E. and Roberts, D. (2012) The role of ownership in determining the rural economic benefits of onshore wind farms. Journal of Agricultural Economics. 63 (2): $331-360$

Rey S.J., West G.R. and Janikas M.V. (2004) Uncertainty in Integrated Regional Models, Economic Systems Research, 16:3, 259-277.

Robinson, S., Cattaneo, A. and El-Said, M. (2001) Updating and Estimating a Social Accounting Matrix Using Cross Entropy Methods, Economic Systems Research, 13 (1): 47-64.

Scottish Government (2015) Tenanted Agricultural Land in Scotland 2014.

Statistical Publication. Agriculture Series.

http://www.gov.scot/Publications/2015/04/2935 (Accessed January 2016)

Scottish Government (2016a) Local Authority Map of Scotland http://www.gov.scot/Topics/Statistics/19972/21085 (Accessed January 2017)

Scottish Government (2016b) Scottish Government Urban Rural Classification http://www.gov.scot/Topics/Statistics/About/Methodology/UrbanRuralClassification (Accessed January 2017)

Simola, A., Kinnunen, J., Törmä, H. and Kola, J. (2010) Bioenergy production in Finland and its effects on regional growth and employment. Paper presented at the IAMO Forum, 16-18 June 2010, Halle, Germany.

Sckokai P and Moro D. "Modeling the reforms of the Common Agricultural Policy for arable crops under uncertainty." American Journal of Agricultural Economics (2006) 88:43-56.

Stroud, A. H. (1957). Remarks on the disposition of points in numerical integration formulas. Mathematical Tables and Other Aids to Computation, 11(60):257-261.

Sutherland, L, Holstead, K., Brown, C and Schwartz, G. (2014) On-Farm Wind Energy Production in Aberdeenshire.

http://farmpath.hutton.ac.uk/sites/www.farmpath.eu/files/FinalAberdeenshirerenewabl es.pdf

Thurlow J (2008) "A Recursive Dynamic CGE Model and Microsimulation Poverty Module for South Africa" IFPRI, Washington. Available online www.tips.org.za/files/2008/Thurlow_J_SA_CGE_and_microsimulation_model_Jan08 .pdf

Trink, T., Schmid, C., Schinko, T., Steininger, K., Loibnegger, T., Kettner, C., Pack, A., and Töglhofer. (2010) Regional economic impacts of biomass based energy service use: A comparison across crops and technologies for East Styria, Austria. Energy Policy, 38: 5912-5926.

Valenzuela, E, T W. Hertel, R Keeney and J Jeffrey (2007) Assessing Global Computable General Equilibrium Model Validity Using Agricultural Price Volatility American Journal of Agricultural Economics, . 89: 383-397 
Verma, M, T. W Hertel, and E Valenzuela (2011) Are The Poverty Effects of Trade Policies Invisible? The World Bank Economic Review, 25:190-211

\author{
Waters, E.C., Holland, D.W. and Weber, B.A. (1997) Economic impacts of a property \\ tax limitation: A computable general equilibrium analysis of Oregon's measure 5, \\ Land Economics, 73(1), 72-89.
}

\footnotetext{
i The equivalent model for commercial developers would be qualitatively similar to that presented in the sense that such developers would also face spatial differences in costs and returns across locations. However they might also benefit from economies of scale and more uniform costs of capital.

${ }^{\text {ii }}$ Consistent with the idea that developers in our model typically represent farmers, they are assumed to be price takers.

iii Includes fixed planning application costs.

${ }^{\text {iv }}$ As the model is being used for illustrative purposes for simplicity we do not discounting expected revenue over the production phase.

${ }^{\mathrm{v}}$ The results for these simulations are available from the authors on request.

${ }^{\text {vi }}$ For example, experimentation for a case where 23 parameters were allowed to vary, the LP has more than 2500 constraints but a quadrature with 1000 points was found.

vii As an indication, we calculated the average absolute relative errors for the analysis reported in section 4 and these were found to be less than 0.12 percent for the expected value and less than 0.23 percent for the second moment.

viii Given the structure of the model it was not possible to both have endogenously determined capital stock and to explore the impact of exogenous changes in agricultural capital as in the investment scenario.. Therefore capital stock in each sector is treated as fixed.

ix An abridged mathematical statement of the model can be accessed via the Economic Systems Research website.

${ }^{x} \mathrm{ROC}$ are a form of Green Certificates, and, prior to the introduction of FiTs, were the primary mechanism for supporting the renewable energy sector in the UK.

xi Theoretically it can be argued that introducing a random shock should be accompanied by allowing for uncertainty in agent decision making but this is beyond the scope of the standard CGE approach applied in the paper.

${ }_{\text {xii }}$ In the simulations allowing for uncertainty, the size of the impacts differ but the qualitative effects are the same.
} 
Figure 1: The basic SAM structure

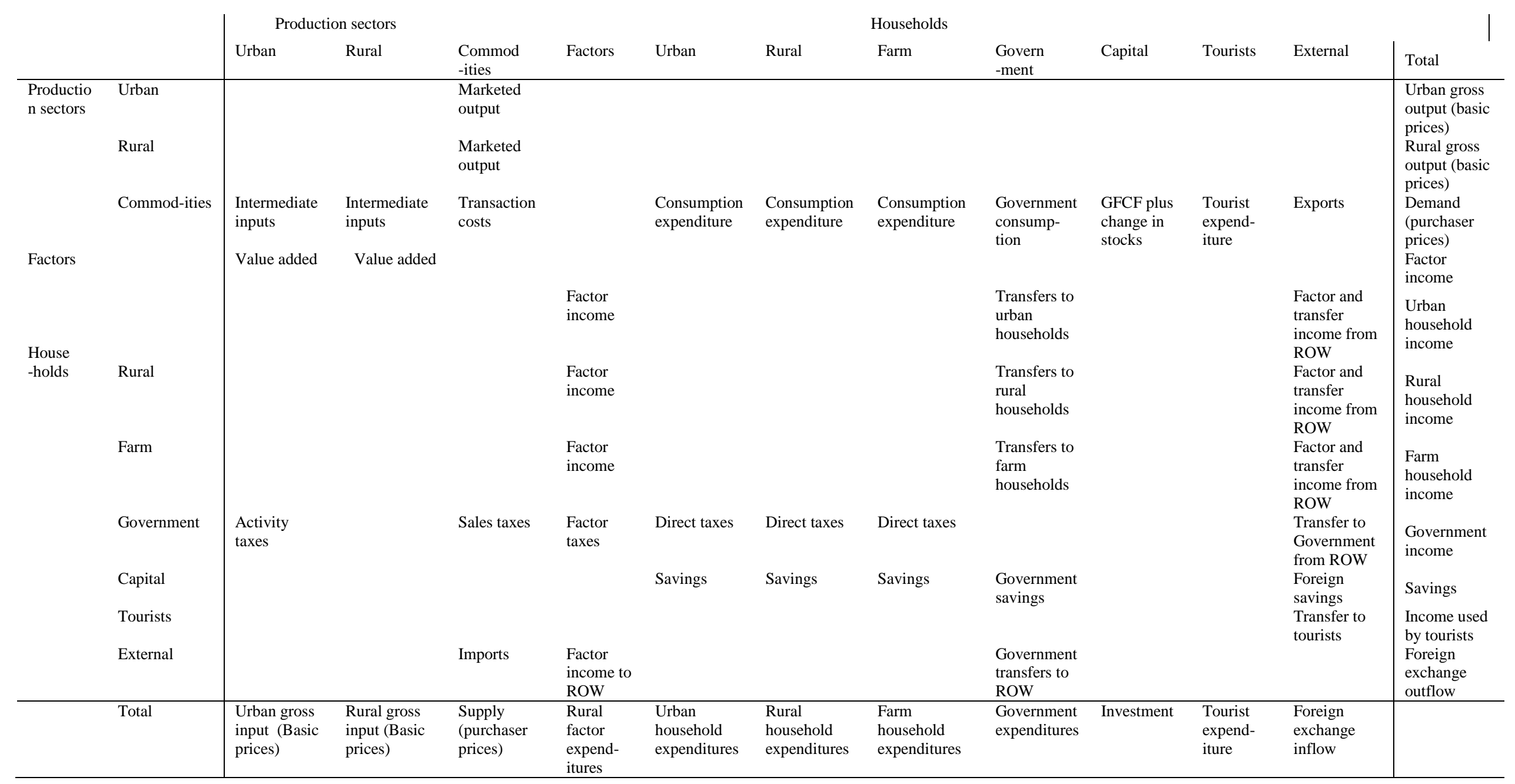


Table 1: Summary information from the North East Scotland SAM, 2005.

\begin{tabular}{lr}
\hline & North East Scotland \\
\hline GDP $(£ \mathrm{~m})$ & 8,852 \\
Rural Share (\%) & 34 \\
Urban Share (\%) & 66 \\
\hline
\end{tabular}

Sectoral contributions to value added (£m):

\begin{tabular}{|c|c|c|}
\hline Rural Area & Agriculture & $83.5(2.8 \%)$ \\
\hline & Forestry & $9.0(0.3 \%)$ \\
\hline & Fishing & $50.5(1.7 \%)$ \\
\hline & Other Primary & $87.8(2.9 \%)$ \\
\hline & Food processing & $141.6 \quad(4.7 \%$ \\
\hline & Wood processing & $66.2(2.2 \%)$ \\
\hline & Energy & $48.8(1.6 \%)$ \\
\hline & Other Secondary & $678.9(22.6 \%)$ \\
\hline & Tertiary & $1,830.2(61.0 \%)$ \\
\hline Urban Area & Primary* & 601.9 (10.3\%) \\
\hline & Secondary & 890.5 (15.2\%) \\
\hline & Tertiary & $4,363.3(74.6 \%)$ \\
\hline Total househ & income $(£ \mathrm{~m})$ & 7,186 \\
\hline Urban $\mathrm{Hl}$ & & 52.5 \\
\hline Rural HH & & 45.9 \\
\hline Small far & $I H(\%)$ & 1.0 \\
\hline Large far & $H H(\%)$ & 0.5 \\
\hline Total value $c$ & xports(£m) & 10,902 \\
\hline Total value c & ports $(£$ & 9,590 \\
\hline
\end{tabular}

*Includes value-added from activities classified under oil extraction within the region 
Table 2: Typical annual costs and revenues per MW Installed capacity (£m 2005)

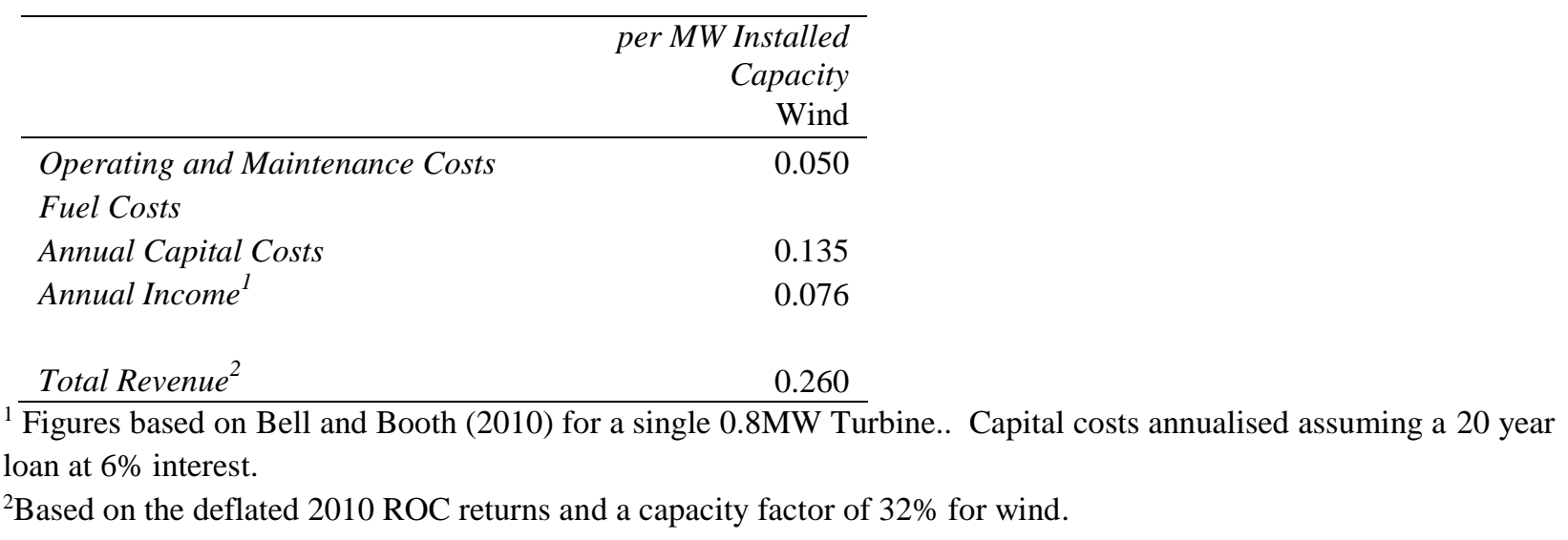


Table 3: Comparison of GDP impacts

\begin{tabular}{lccrr}
\hline & \multicolumn{2}{c}{ Deterministic shock } & \multicolumn{2}{c}{ Asymmetric shock } \\
\multicolumn{2}{c}{ Consumption } & Investment & Consumption & Investment \\
\hline Change in GDP (£million) & & & \\
Total & 100.210 & 116.694 & 106.443 & 122.841 \\
& & & $(0.340)$ & $(0.312)$ \\
Rural & & & & \\
sectors & 108.574 & 128.056 & 115.334 & 134.704 \\
& & & $(0.340)$ & $(0.312)$ \\
Urban & & & & \\
sectors & -8.364 & -11.362 & -8.892 & -11.863 \\
& & & $-(0.340)$ & $-(0.279)$ \\
\hline \multirow{2}{*}{ Total } & 1.132 & 1.318 & 1.202 & 1.388 \\
& & & $(0.340)$ & $(0.312)$ \\
Rural & & & & \\
sectors & 3.623 & 4.273 & 3.849 & 4.495 \\
& & & $(0.340)$ & $(0.309)$ \\
Urban & & & -0.152 & -0.203 \\
sectors & -0.143 & -0.194 & $-(0.342)$ & $-(0.276)$ \\
\hline
\end{tabular}

(Values in parentheses are Coefficients of Variation) 
Table 4: Comparison of sector GDP impacts (£m)

\begin{tabular}{|c|c|c|c|c|}
\hline & \multicolumn{2}{|c|}{ Deterministic shock } & \multicolumn{2}{|c|}{ Uncertain shock } \\
\hline & Consumption & Investment & Consumption & Investment \\
\hline \multicolumn{5}{|c|}{ Change in GDP (£million) } \\
\hline Agric & -0.084 & 18.336 & $\begin{array}{l}-0.089 \\
(0.03)\end{array}$ & $\begin{array}{l}18.226 \\
(2.303)\end{array}$ \\
\hline \multicolumn{5}{|l|}{ Rural } \\
\hline Manufacturing & 111.151 & 113.488 & $\begin{array}{r}118.072 \\
(40.176)\end{array}$ & $\begin{array}{c}120.388 \\
(40.387)\end{array}$ \\
\hline Rural Services & -2.0889 & -2.418 & $\begin{array}{r}-2.218 \\
(0.75)\end{array}$ & $\begin{array}{r}-2.540 \\
(0.755)\end{array}$ \\
\hline \multicolumn{5}{|l|}{ Urban } \\
\hline Manufufacturing & -0.897 & -0.628 & $\begin{array}{c}-0.959 \\
(0.339)\end{array}$ & $\begin{array}{l}-0.692 \\
(0.313)\end{array}$ \\
\hline Urban Services & -4.465 & -5.168 & $\begin{array}{r}-4.744 \\
(1.605)\end{array}$ & $\begin{array}{r}-5.429 \\
(1.611) \\
\end{array}$ \\
\hline \multicolumn{5}{|c|}{ Percentage change from base year values } \\
\hline Agric & -0.096 & 21.113 & $\begin{array}{l}-0.102 \\
(0.035)\end{array}$ & $\begin{array}{l}20.987 \\
(2.652)\end{array}$ \\
\hline \multicolumn{5}{|l|}{ Rural } \\
\hline Manufacturing & 11.880 & 12.130 & $\begin{array}{r}12.620 \\
(4.294)\end{array}$ & $\begin{array}{l}12.868 \\
(4.317)\end{array}$ \\
\hline Rural Services & -0.114 & -0.132 & $\begin{array}{l}-0.121 \\
(0.041)\end{array}$ & $\begin{array}{l}-0.139 \\
(0.041)\end{array}$ \\
\hline \multicolumn{5}{|l|}{ Urban } \\
\hline Manufacturing & -0.101 & -0.070 & $\begin{array}{r}-0.108 \\
(0.038)\end{array}$ & $\begin{array}{r}-0.078 \\
(0.035)\end{array}$ \\
\hline Urban Services & -0.102 & -0.118 & $\begin{array}{r}-0.109 \\
(0.037)\end{array}$ & $\begin{array}{l}-0.124 \\
(0.037)\end{array}$ \\
\hline
\end{tabular}

(Values in parentheses are Coefficients of Variation) 
Table 5: Welfare impacts: Percentage change in EV from base year consumption

\begin{tabular}{lllrr}
\hline & \multicolumn{2}{c}{ Deterministic shock } & \multicolumn{2}{c}{ Uncertain shock } \\
& Consumption & Investment & Consumption & Investment \\
\hline Urban & -0.732 & -0.059 & -0.78 & -0.075 \\
Households & & & $-(0.346)$ & $-(0.933)$ \\
& & & & \\
Rural & -0.792 & -0.003 & -0.843 & -0.02 \\
Households & & & $-(0.344)$ & $-(3.250)$ \\
& & & & \\
Farm & 19.993 & 9.191 & 21.221 & 9.103 \\
h'hold & & & $(0.336)$ & $(0.109)$ \\
small farms & & & & \\
Farm & 75.812 & 10.932 & 80.475 & 10.83 \\
h'hold & & & $(0.336)$ & $(0.110)$ \\
large farms & & & & \\
& -0.645 & -0.128 & -0.687 & -0.143 \\
Non-profit & & & $-(0.344)$ & $-(0.531)$ \\
insit. & & & & \\
Total & -0.174 & 0.098 & -0.187 & 0.082 \\
& & & $-(0.374)$ & $(0.610)$ \\
& & & & \\
\hline
\end{tabular}

(Values in parentheses are Coefficients of Variation) 
Online Appendix. Allowing for uncertainty in exogenous shocks to CGE models: The case of a new renewable energy sector

\section{Abridged Mathematical Statement of Model}

\begin{tabular}{|c|c|}
\hline Prices & \\
\hline Absorption: & $P Q_{c}\left(1-t q_{c}\right) Q Q_{c}=P D D_{c} Q D_{c}+P M_{c} Q M_{c}$ \\
\hline Marketed output value: & $P X_{c} Q X_{c}=P D S_{c} Q D_{c}+P E_{c} Q E_{c}$ \\
\hline Activity Price & $P A_{a}=\sum_{c \in C} \theta_{a c} p x_{a c}$ \\
\hline $\begin{array}{l}\text { Aggregate Intermediate } \\
\text { Input Price }\end{array}$ & $P I N T A_{a}=\sum_{c \in C} P Q_{c} i c a_{a c}$ \\
\hline Consumer Price Index & $\overline{C P I}=\sum_{c \in C} P Q_{c} c w t s_{c}$ \\
\hline Activity revenue/costs & $P A_{a}\left(1-t a_{a}\right) Q A_{a}=P V A_{a} Q V A_{a}+P I N T A_{a} Q I N T A_{a}$ \\
\hline Production and Trade & \\
\hline $\begin{array}{l}\text { Demand for aggregate } \\
\text { value-added: }\end{array}$ & $Q V_{a}=i v a_{a} Q A_{a}$ \\
\hline $\begin{array}{l}\text { Demand for aggregate } \\
\text { intermediate input: }\end{array}$ & $Q I N T A_{a}=\operatorname{int} a_{a} Q A_{a}$ \\
\hline $\begin{array}{l}\text { Value added and factor } \\
\text { demands: }\end{array}$ & $Q V A_{a}=a_{a}^{v a}\left(\sum_{f \in F} \delta_{f a}^{v a} Q F_{f a}^{-\rho_{a}^{v a}}\right)^{-\frac{1}{\rho_{a}^{v a}}}$ \\
\hline $\begin{array}{l}\text { Disaggregated } \\
\text { Intermediate Input } \\
\text { Demand }\end{array}$ & $Q I N T_{c a}=i c a_{c a} Q I N T A_{a}$ \\
\hline Commodity Output by & $Q X A C_{a c}=\theta_{a c} Q_{a}$ \\
\hline
\end{tabular}




\begin{tabular}{|c|c|}
\hline Activity & \\
\hline $\begin{array}{l}\text { Output transformation } \\
\text { (CET function): }\end{array}$ & $Q X_{c}=\alpha_{c}\left(\delta_{c} Q E_{c}^{\rho_{c}}+\left(1-\delta_{c}\right) Q D_{c}^{\rho_{c}}\right)^{\frac{1}{\rho_{c}}}$ \\
\hline $\begin{array}{l}\text { Composite supply } \\
\text { (Armington function): }\end{array}$ & $Q Q_{c}=\alpha_{c}^{q}\left(\delta_{c}^{q} Q M_{c}^{-\rho_{c}^{q}}+\left(1-\delta_{c}^{q}\right) Q D_{c}^{-\rho_{c}^{q}}\right)^{-\frac{1}{\rho_{c}^{q}}}$ \\
\hline $\begin{array}{l}\text { Output aggregation } \\
\text { function: }\end{array}$ & $Q X_{c}=\alpha_{c}^{a c}\left(\sum_{\alpha \in A} \delta_{a c}^{a c} Q X A C_{a c}{ }^{-\rho_{c}^{a c}}\right)^{\frac{1}{\rho_{c}^{a c}-1}}$ \\
\hline $\begin{array}{l}\text { Labour Supply (Thurlow, } \\
\text { 2008) }\end{array}$ & $\frac{Q F S_{f}}{Q F S_{f}^{0}}=\left(\frac{R W F_{f}}{R W F_{f}^{0}}\right)^{\text {etas, }}$ \\
\hline $\begin{array}{l}\text { Average Real Wage } \\
\text { (Skilled and Unskilled } \\
\text { Labour) }\end{array}$ & $R W F_{f}=\left(\frac{Y F_{f}}{Q F S_{f}}\right) /\left(\frac{C P I_{f}}{C P I_{f}^{0}}\right)$ \\
\hline Institution Block & \\
\hline Factor income: & $Y F_{f}=\sum_{a \in A} W F_{f} \cdot W F D I S T_{f a} \cdot Q F_{f a}$ \\
\hline Institutional factor incomes & $Y I F_{i f}=\operatorname{shif}_{i f}\left(1-\right.$ shifor $\left._{f}\right) Y F_{f}$ \\
\hline $\begin{array}{l}\text { Income of domestic non- } \\
\text { government institutions }\end{array}$ & $Y I_{i}=\sum_{f \in F} Y I F_{f}+\sum_{i \in I N S D N G} T R I I_{i i^{\prime}}+t r n s f_{i g o v}+\operatorname{trns} f i_{O R}$ \\
\hline Infra-institutional transfers & $\operatorname{TRII}_{i i^{\prime}}=\operatorname{shii}_{i i^{\prime}}\left(1-m p s_{i}\right)\left(1-\operatorname{tins}_{i}\right) Y I_{i}$ \\
\hline $\begin{array}{l}\text { Household consumption } \\
\text { expenditure }\end{array}$ & $E H_{h}=\left(1-\sum_{i \in I N S D N G} s h i i_{i h}\right)\left(1-m p s_{h}\right)\left(1-t i n s_{h}\right) Y I_{h}$ \\
\hline $\begin{array}{l}\text { Household consumption } \\
\text { demand for commodities }\end{array}$ & $P Q_{c} Q H_{c h}=P Q_{c} \gamma_{c h}^{m}+\beta_{c h}^{m}\left(E H_{h}-\sum_{c \in C} P Q_{c} \gamma_{c h}^{m}\right)$ \\
\hline Government revenue: & \\
\hline
\end{tabular}




\begin{tabular}{|c|c|}
\hline & $Y G=\sum_{i \in I N S D N G} \operatorname{tins}_{i} Y I_{i}+\sum_{a \in A} t a_{a} P A_{a} Q A_{a}+\sum_{c \in C} t q_{c} P Q_{c} Q Q_{c}+\sum_{f \in F} Y I F_{\text {govf }}+t r n s f_{\text {gov } O R}$ \\
\hline Government expenditure & $E G=\sum_{c \in C} P Q_{c} \overline{Q G}_{c}+\sum_{i \in I N S D N G} \operatorname{transf}_{i g o v}$ \\
\hline \multicolumn{2}{|l|}{ System Constraint Block } \\
\hline Factor Market: & $\sum_{a \in A} Q F_{f a}=Q F S_{f}$ \\
\hline $\begin{array}{l}\text { Composite commodity } \\
\text { markets }\end{array}$ & $Q Q_{c}=\sum_{a \in A} Q I N T_{c a}+\sum_{h \in H} Q H_{c h}+{\overline{Q G_{c}}}+\overline{Q I N V}_{c}$ \\
\hline Current account balance: & $\sum_{c \in C M} p w m_{c} Q M_{c}+\sum_{f \in F} s h i f o r_{f} Y F_{f}=\sum_{c \in C E} p w e_{c} Q E_{c}+\sum_{i \in I N S D} t r n s f r_{i O R}+S A V O R$ \\
\hline Government balance: & $Y G=E G+G S A V$ \\
\hline Saving-Investment Balance: & $\sum_{i \in I N S D N G} m p s_{i}\left(1-\right.$ tins $\left._{i}\right) Y I_{i}+G S A V+S A V O R=\sum_{c \in C} P Q_{c} \overline{Q I N V_{c}}$ \\
\hline
\end{tabular}

\section{Definitions of Model Parameters/Variables}

\section{Sets}

$$
\begin{aligned}
& a \in A \\
& c \in C \\
& c \in C M \\
& c \in C E \\
& f \in F \\
& i \in I S N D N G \\
& h \in H
\end{aligned}
$$

\section{Parameters}

$$
\begin{aligned}
& \alpha_{a}^{v a} \\
& \alpha_{c} \\
& \alpha_{c}^{q} \\
& \alpha_{c}^{a c}
\end{aligned}
$$

activities (disaggregated according to rural-urban status)

commodities

regionally imported commodities

regionally exported commodities

factors (disaggregated according to rural-urban status)

regional non-government institutions

regional households (disaggregated according to rural-urban status)

efficiency parameter in the CES value added function

CET function shift parameter

Armington function shift parameter

shift parameter for domestic commodity aggregation function 
$\beta_{c h}^{m}$

$\delta_{a}^{a}$

$\delta_{f a}^{v a}$

$\delta_{c}$

$\delta_{c}^{q}$

$\delta_{c}^{a c}$

$\gamma_{c h}^{m}$

$\rho_{a}^{a}$

$\rho_{a}^{v a}$

$\rho_{c}^{t}$

$\rho_{c}^{a c}$

$\theta_{a c}$

$c w t s_{c}$

etas

iva $a$

int $a_{a}$

$t q_{c}$

$t a_{a}$

tf $f$

tins $_{i}$

shif $_{\text {if }}$

shifor $_{f}$

trnsfr $_{i f}$

$\mathrm{pwm}_{\mathrm{c}}$

$p w e_{c}$

\section{Exogenous Variables}

$\overline{Q I N V_{c}}$
$\overline{Q G_{c}}$
$Q F S_{f}$
WFDIST $_{f a}$
$\operatorname{TINS}_{i}$
$\mathrm{PE}_{c}$
$\mathrm{PM}_{c}$

marginal share of consumption spending on marketed commodity $c$ for household $h$ CES activity function share parameter

CES value-added share parameter for factor $f$ in activity $a$

CET function share parameter

Armington function share parameter

share parameter for domestic commodity aggregation function

subsistence consumption of commodity $c$ for household $h$

CES production function exponent

CES value-added function exponent

CET function exponent

domestic commodity aggregation function exponent

yield of output c per unit of activity $a$.

consumer price index weights

labour supply elasticity factor $f$

quantity of value-added per activity unit

quantity of aggregate intermediate input per activity unit

rate of sales tax

tax rate for activity $a$

direct tax rate for factor $f$

income rate for institution $i$

share for regional institution $i$ in income of factor $f$

share for out of region ownership of income of factor $f$

transfer from factor $f$ to institution $i$

out of region price of regional imports

out of region price of regional exports

quantity of investment demand for commodity

government consumption demand for commodity

quantity of factor supplied (land, capital)

wage distortion factor for factor $f$ in activity $a$ (skilled, unskilled labour, land)

direct tax rate for institution $i$

price of regional exports

price of regional imports 


\section{Endogenous Variables}

\begin{tabular}{|c|c|}
\hline$P Q_{c}$ & composite commodity price \\
\hline$P D D_{c}$ & demand price for commodity produced and sold within region \\
\hline$P X_{c}$ & aggregate producer price for commodity \\
\hline$P X A C_{a c}$ & producer price of commodity $c$ for activity $a$ \\
\hline$P D S_{c}$ & supply price for commodity produced and sold within region \\
\hline$P V A_{a}$ & value-added price (factor income per unit of activity) \\
\hline$Q A_{a}$ & quantity (level) of activity \\
\hline$Q Q_{c}$ & quantity of goods supplied to regional market (composite supply) \\
\hline$Q D_{c}$ & quantity sold within regional of regional output \\
\hline$Q E_{c}$ & quantity of regional exports of commodity $c$ \\
\hline$Q F S_{f}$ & quantity of factor supplied (skilled \& unskilled labour) \\
\hline$Q M_{c}$ & quantity of regional imports of commodity $c$ \\
\hline$Q X A C_{a c}$ & quantity of output of commodity $c$ from activity $a$ \\
\hline$Q X_{c}$ & aggregate quantity of regional output of commodity \\
\hline$Q V A_{a}$ & quantity of (aggregate) value-added activity $a$ \\
\hline$Q_{I N T A_{a}}$ & quantity of aggregate intermediate input activity $a$ \\
\hline$Q I N T_{c a}$ & quantity of commodity $c$ as intermediate input to activity $a$ \\
\hline$Q F_{f a}$ & quantity demanded of factor $f$ from activity $a$ \\
\hline$Q H_{c h}$ & quantity consumed of commodity $c$ by household $h$ \\
\hline$Y F_{f}$ & income of factor $f$ \\
\hline$W F_{f}$ & average price of factor $f$ \\
\hline$Y I F_{i f}$ & income to domestic institution $i$ from factor $f$ \\
\hline$Y I_{i}$ & income of regional nongovernment institution \\
\hline$E H_{h}$ & consumption spending for household \\
\hline$Y G$ & government revenue \\
\hline$E G$ & government expenditures \\
\hline$G S A V$ & government savings \\
\hline$S A V O R$ & out of region saving \\
\hline$R W F_{f}$ & average real wage by factor \\
\hline$m p s_{i}$ & marginal propensity to save for regional non-government institution \\
\hline$W_{F D I S T}$ & wage distortion factor for factor $f$ in activity $a$ (capital) \\
\hline
\end{tabular}

